\title{
VIEWPOINT Adaptive management: The cornerstone of climate-smart agriculture
}

\author{
Ernest C. Shea
}

0

ver the past decade, I have been supporting and collaborating with visionary farmers, ranchers, and foresters in the 25x'25 Alliance and Solutions from the Land Dialogue. Together, we have been on a mission to "redefine" the core function of agriculture. Long known and respected for the role the sector plays in producing food, feed and fiber, we have been working, both domestically and globally, to ensure that producers are recognized, valued, and compensated for the full range of goods and services they deliver from the land.

While providing the basic staples of life, growers also produce clean energy, water, and air; maintain and enhance biodiversity; create high value ecosystem services; and sequester carbon (C) and other greenhouse gases that exacerbate global warming. In short, the agriculture and forestry sectors and their aligned value chain partners deliver multiple "solutions from the land."

In the lower $\mathrm{C}$ future that is emerging, however, farmers will encounter a myriad of opportunities and challenges that will compromise their ability to provide land-based solutions that will benefit both producers and the environment. Feeding and fueling a world population that will reach over nine billion by the year 2050 will most certainly create new and valuable markets for the goods and services that come from the land. Satisfying these new demands and markets in ways that do not degrade ecosystems, however, will remain a formidable challenge for producers for decades to come. Climate change will only exacerbate this challenge.

Through an extensive analysis of peerreviewed scientific reports, the volunteer leaders I have been working with have come to understand and accept that climate change is happening, is an increasing risk, and that climate-related disruptions will make it exceedingly more difficult to achieve the $25 x^{\prime} 25$ national goal that we helped secure: "By 2025, America's farms,

Ernest C. Shea is the principal at Natural Resource Solutions, LLC; president of Solutions from the Land; and coordinator of the $25 x^{2} 25$ Alliance, Lutherville, Maryland. forests, and ranches will provide 25 percent of the total energy consumed in the United States, while continuing to produce safe, abundant, and affordable food, feed, and fiber" (25x'25 Alliance 2014). Through our work with the Solutions from the Land Dialogue, we went on to conclude that climate change will create a "less predictable, less stable environment for farmers, foresters, and ranchers, in which business as usual may not be enough to meet the needs of food, feed, fuel, and fiber in a rapidly growing world" (Solutions from the Land 2013).

These conclusions and concerns were validated earlier this year when the US government released its latest National Climate Assessment Report (US Global Change Research Program 2014). Authored by scores of highly respected agronomists, soil scientists, meteorologists, climatologists, economists, plant and animal physiologists, and other experts that producers rely on to make sound agronomic business decisions, the report concluded that climate change is unequivo$\mathrm{cal}$ and that agriculture and forestry will be on the front lines with those most impacted by its effects. "Climate disruptions to agricultural production have increased in the past 40 years and are projected to increase over the next 25 years. By midcentury and beyond, these impacts will be increasingly negative on most crops and livestock" (US Global Change Research Program 2014). Among other conditions, the report calls on producers and land managers to expect increases in the frequency of extreme weather events, which will cause significant erosion, runoff, and nutrient leaching challenges; prolonged droughts; increased pressure from pests, weeds, and invasive species; and higher nighttime temperatures, which, among other things, will impede crop pollination and lead to the potential for lower yields.

As significant as these challenges are, the good news is that there any number of actions that farmers, ranchers, and foresters can take to adapt to changing climatic conditions. As we highlighted in the report Agriculture and Forestry in a Changing Climate: Adaptation Recommendations, "adaptation strategies come in many different forms, but typically fall into three categories: actions to increase resistance to changes in climate in order to maintain existing practices; actions to improve resilience by investing in steps that preempt disasters and restore systems in the wake of them; and actions to transform operations (25x'25 Alliance 2013).

Adaptation strategies and actions will be needed in multiple areas. In the research arena, adaptation priorities should include studies on the impact of soil moisture on local climates; the effect of higher temperatures on seasonal water use patterns; the impacts of changing moisture and temperature regimes on nutrient cycling; and the role of microorganisms in soil $\mathrm{C}$ and nitrogen $(\mathrm{N})$ stabilization. In the production practices arena, new infrastructure and upgrades to existing infrastructure will be needed to meet climate challenges, and farms, ranches, and forests will need to be managed differently to reduce risks posed by pests, weeds, fires, stronger storms, and increasingly erratic precipitation. The ways we manage risk will need to change as well. While crop insurance and government disaster payments have comprised the primary safety net for producers over the past several decades, relief programs and tools like these will likely not be adequate to meet the demands for assistance that climate change will likely create. For that reason, increased investments in adaptation measures to help producers resist and mitigate impacts will be required.

One of the most important set of tools in our adaptation tool box will be innovative conservation systems and practices that improve soil health. The same practices that we encourage producers to use or install to improve productivity, minimize soil erosion, and protect water quality also are primary tools for adapting to and mitigating the impacts of climate change. The $25 x$ '25 Adaption Work group identified the following conservation practices which can simultaneously protect the productive capacity of land, the environment, and sequester C:

- Increase soil water-holding capacity by improving soil organic matter content. With heavier rainfall events creating problems for many producers, the implementation of practices to increase soil organic matter will help to prevent ero- 
sion and loss of valuable nutrients. It will also make crops more resilient to drought by retaining additional water.

- Engage in conservation tillage practices to improve soil quality. For many farmers, conservation tillage has become a standard practice for dealing with erosion, runoff, soil compaction, and declining organic matter. In addition to reducing input costs, conservation tillage can protect soils from heavier rainfalls and/or prolonged drought.

- Plant cover crops to provide additional soil protection. Like conservation tillage, cover crops are becoming a popular tool for increasing soil organic matter and preventing erosion and runoff, especially during winter and early spring.

- Explore the use of conservation buffers to prevent runoff and enhance ecosystem services. In addition to preventing runoff, conservation buffers filter water, create habitat, offer shade for livestock, reduce water temperature, increase dissolved oxygen, and prevent algal blooms in waterways. Research even suggests that buffers, such as those composed of miscanthus (Miscanthus spp.) or switchgrass (Panicum virgatum L.), can protect against chemical drift (USDA NRCS 2000).

- Utilize wetlands and new field drainage practices. Heavy rainfalls and changes in the timing of precipitation may require new drainage networks. A number of options exist to meet this need, including buffer strips that scavenge nutrients and wetlands for additional filtration. Controlled drainage techniques, such as using a flashboard riser to allow water in a drainage outlet to be raised or lowered, can improve production and maximize nutrient use.

- Diversify and lengthen cropping systems that enhance soil structure. Longer crop rotations can help break up pest and weed cycles, thereby reducing input costs and enhancing the soil's productive capacity.

- Consider biochar to improve soil health. Biochar is a charcoal byproduct created by burning biomass at slow and low heat. Though additional field research will be needed, biochar has been demonstrated to have a number of benefits as a soil amendment, including improving nutrients, tilth, and water management. In addition, it is a means of sequestering carbon into the soil (Biochar Farms).

- Engage in irrigation practices that improve water-use efficiency. In many regions that already rely on irrigation, the climate is expected to become drier and create new demand for water-saving irrigation practices. In addition to conducting regular maintenance and audits on existing systems, many producers are recycling water, changing to drip systems, and using precision irrigation to target specific areas of their fields with the exact amount of water needed. Climate change poses real and substantial challenges for agriculture globally-challenges that the status quo is unlikely to meet. Effective adaptation management strategies offer the agriculture and forestry sectors ways to manage risk and increase production while simultaneously improving soil, water, air quality, and biodiversity. However, to ensure that these strategies are implemented at the scale necessary to make agriculture more resilient, greater and improved communication, coordination, and cooperation among farm and forestry organizations, governments, international and regional research groups, businesses, and civil societies are needed.

To help meet this need, this past September at a United Nations Climate Change Summit in New York City, New York, several hundred entities, including Solutions from the Land, banded together and launched the Global Alliance for Climate-Smart Agriculture. The Alliance will serve as an information clearing house and learning platform for pursuing the three pillars of climate-smart agriculture: sustainably increasing agricultural productivity and livelihoods, adapting and building greater resilience in agricultural and forestry systems, and reducing and/or removing greenhouse gas emissions associated with agriculture.

The launch of this alliance marked a major milestone in the quest to overcome the food security, nutrition, and poverty challenges that climate change will create. Rather than following the usual United Nations government-centric approach to solving world problems, through the Global-Alliance for Climate-Smart Agriculture, farmer leaders will be equal partners with governments, businesses, and civil society organizations in setting priorities and shaping policy decisions on strategies and tactics for adapting and building resilience to changing climatic conditions.

Closer to home, similar platforms or forums are needed to enhance multistakeholder collaboration in advancing adaptive management strategies and programs across the United States and North America, and efforts are underway through Solutions from the Land to support and facilitate their development. Initial areas of focus for these efforts might include sharing knowledge and helping educate agricultural and forestry leaders on the potential impacts of climate change in ways relevant to their daily lives; equipping producers with the tools and knowledge they need to make informed decisions and manage new risks under changing conditions; advocating for needed changes in land use practices, research, education, and policy; and inspiring agricultural and forest sector leaders to become leaders in the broader discussion of climate change, including adaptation and mitigation.

As controversial as the topic of climate change is in some circles, we really only have a few choices. We can burry our heads in the sand and hope the problem goes away; we can align with the deniers and bet "the farm," so to speak, that the scientists are wrong; or we can prepare for what is coming by developing and adopting comprehensive adaptive management strategies that will enhance the resiliency and sustainability of our operations. The leaders I work closely with chose the latter option, and we hope others will as well.

\section{REFERENCES}

25 x'25 Alliance. 2013. Agriculture and Forestry in a Changing Climate:Adaptation Recommendations. Lutherville, MD: 25x'25 Alliance.

25 x'25 Alliance. 2014. 25x'25 Alliance Homepage. Lutherville, MD: 25x'25 Alliance. http:// www.25x25.org/index.php.

Biochar Farms. Potential benefits of biochar. http:// biocharfarms.org/farming/.

Solutions from the Land. 2013. Developing a New Vision for United States Agriculture, Forestry, and Conservation. Lutherville, MD: Solutions from the Land. http://sfldialogue.net/Resources/ SFL_Pathways_Report.pdf.

USDA NRCS (Natural Resources Conservation Service). 2000. Conservation buffers to reduce pesticide losses," March 2000. http://www.in.nrcs. usda.gov/technical/agronomy/newconbuf.pdf.

US Global Change Research Program. 2014 National Climate Report. Washington, DC: US Global Change Research Program. http:// nca2014.globalchange.gov/report. 